\title{
Radiologic evaluation of congenital anomalies of anterior and posterior arch of atlas in Omani subjects
}

\author{
Ghaliya Al Hinai ${ }^{1}$, Mai Al Shandoodi ${ }^{2}$, Srinivasa Rao Sirasanagandla ${ }^{3}$, Salwa Al Sarhani ${ }^{4}$, \\ Humoud Al Dhuhli ${ }^{4}$, Sanjay Jaju ${ }^{5}$, Mohamed Al Mushaiqri ${ }^{3}$ \\ ${ }^{1}$ Radiology Residency Program, Oman Medical Specialty Board, Muscat, ${ }^{2}$ College of Medicine and Health Sciences, Sultan Qaboos University, Muscat, \\ ${ }^{3}$ Department of Human and Clinical Anatomy, College of Medicine and Health Sciences, Sultan Qaboos University, Muscat, ${ }^{4}$ Department of Radiology \\ and Molecular Imaging, College of Medicine and Health Sciences, Sultan Qaboos University, Muscat, ${ }^{5}$ Department of Family Medicine \& Public \\ Health, College of Medicine and Health Sciences, Sultan Qaboos University, Muscat, Oman
}

\begin{abstract}
The atlas (C1) is known to present congenital anomalies in its anterior and posterior arches. The reported incidence of $\mathrm{Cl}$ anomalies is varied among the ethnic groups. We sought to determine the prevalence and various existing variations of $\mathrm{C} 1$ arch congenital anomalies in Omani subjects. This study was carried out by reviewing the cervical spine computed tomography scans of all the patients who had been referred to the Radiology Department, Sultan Qaboos University Hospital. Descriptive statistics and chi-square test were employed to analyse the data. A total of 663 subjects aged $\geq 18$ years were included in the present study. Overall prevalence of $\mathrm{C} 1$ arch anomalies was $4.37 \%$ with $4.07 \%$ of isolated posterior arch anomalies, $0.3 \%$ of combined anterior and posterior arch anomalies. Among isolated posterior arch anomalies, type A and type B posterior arch defects were found in $3.77 \%$ and $0.3 \%$ of cases, respectively. Atlanto-occipital assimilation was noted in one case of total study subjects. The prevalence rate of $\mathrm{C} 1 \mathrm{arch}$ anomalies is relatively high in Omani subjects. The baseline data of $\mathrm{C} 1$ arch anomalies reported in the present study has a great impact on clinical practice, due to the fact that studying and evaluating the types of congenital anomalies helps in their accurate diagnosis and early intervention.
\end{abstract}

Key words: Spine, Prevalence, Cervical vertebrae, Diagnosis, Radiology

Received May 17, 2021; 1st Revised June 14, 2021; 2nd Revised June 21, 2021; 3rd Revised June 21, 2021;

Accepted June 22, 2021

\section{Introduction}

The atlas (C1) is known to show congenital anomalies in its anterior and posterior arches. Though posterior arch anomalies are well known, the anterior arch anomalies are seldom reported in the literature [1]. Currarino et al. [1] have

\section{Corresponding author:}

Srinivasa Rao Sirasanagandla (i)

Department of Human and Clinical Anatomy, College of Medicine and Health Sciences, Sultan Oaboos University, Al-Khoud 123, Muscat, Oman E-mail: srinivasa@squ.edu.om classified posterior arch anomalies into five types: Type A, failure of fusion of two hemi arches; Type B, defect in one side of the arch, Type C, defects on both sides of arch, Type $\mathrm{D}$, absence of arch except posterior tubercle, and Type E, absence of whole arch including tubercle. Type A is the frequent type and it occurs in 5.4\% of the population and $97 \%$ of all posterior arch defects. When compared to posterior arch, the occurrence of anterior arch anomalies is rare [2]. So far only few cases of anterior arch of $\mathrm{C} 1$ including either absence or clefts have been reported [3].

Anomalies of $\mathrm{C} 1$ may cause atlantoaxial joint instability which necessitates the treatment with a cervical collar or surgery. Furthermore, these anomalies may increase the 
risk of cranio-vertebral and/or cervical injuries [4]. There are reported cases of $\mathrm{C} 1$ arch anomalies that were confused with fractures and resulted in misdiagnosis $[5,6]$. Most of the congenital $\mathrm{C} 1$ arch anomalies are incidental and asymptomatic. However, they may increase the risk of developing myelopathy, anterior rachischisis and early cervical degenerative disc disease $[7,8]$. The knowledge about the occurrence and various types of arch anomalies is clinically important in the current practice of surgery and radiology. To date, prevalence and existing variants of $\mathrm{C} 1$ arch anomalies among Omani population are not known. Hence, we sought to determine the prevalence and various existing variations of congenital anomalies of $\mathrm{C} 1$ arch in Omani patients who were referred for radiological investigation to a tertiary care hospital in Oman.

\section{Materials and Methods}

The present study was conducted by reviewing the cervical spine computed tomography (CT) scans of an indoor and outdoor patients aged $\geq 18$ years, who were referred for head and neck CT scan to the Radiology Department of Sultan Qaboos University Hospital (SQUH) in Oman. In case of more than one cervical CT scan for a patient, the most recent one was included. All patients with the history of spinal fracture and non-Omani nationalities were excluded from the study.

Patients data were collected retrospectively from the “TRACKCARE” system at SQUH from January 2016 till
December 2017. The types of the arch anomalies of $\mathrm{Cl}$ were recorded based on Currarino's classification (Fig. 1) [1]. The characteristic CT appearance of $\mathrm{C} 1$ was used to differentiate the anomalies from fractures. The anomalies are identified by smooth and well-corticated margins without any associated soft tissue swelling. Contrary to this, the fractures usually have irregular jagged borders with associated soft tissue swelling [6]. The prevalence of anterior and posterior arch anomalies was calculated. The study was approved by the Medical Research Ethics Committee, College of Medicine, SQUH (REF. NO. SQU-EC/181/18).

\section{Statistical analysis}

IBM SPSS v. 23 (IBM Corp., Armonk, NY, USA) software was used to analyze the data. Descriptive statistics were applied to evaluate the prevalence of $\mathrm{C} 1$ arch anomalies among different age groups and sex. Chi-square test was used to determine the influence of sex on occurrence of $\mathrm{C} 1 \mathrm{arch}$ anomalies. A $P$-value of $<0.05$ was considered of statistical significance.

\section{Results}

A total of 663 subjects were evaluated in the present study. Among these patients 65.3\% $(n=433)$ were males. Overall prevalence of $\mathrm{C} 1$ arch anomalies was 4.37\% (29/663). Among the observed anomalies, there were $4.07 \%$ of isolated posterior (27/663) arch anomalies, 0.3\% (2/663) of combined anterior and posterior arch anomalies. In males and females,
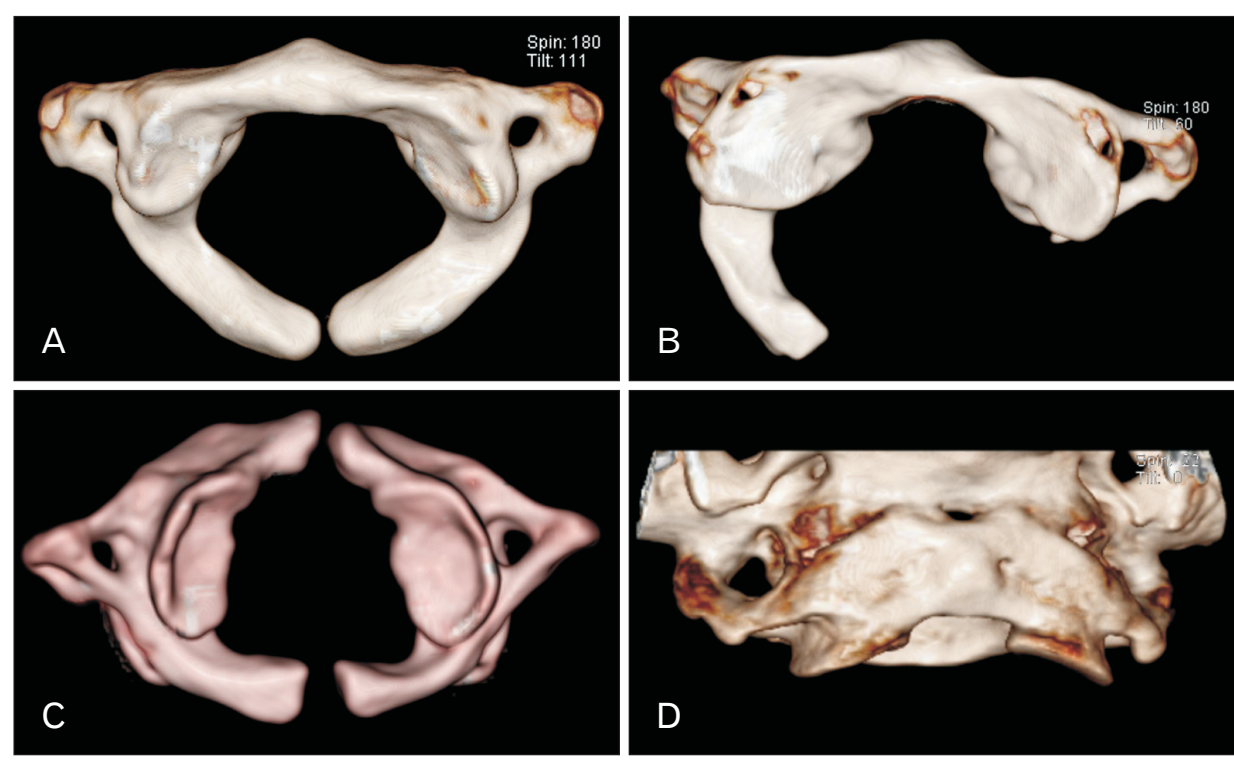

Fig. 1. Three dimensional reconstructed computed tomography scan showing the type $A(A)$, type $B(B)$ posterior arch defects, and combined anterior and posterior arch defect (C). The posterior view (B) of atlantooccipital assimilation (D) is also seen. 
the prevalence of $\mathrm{C} 1$ arch anomalies was found to be $3.69 \%$ $(16 / 433)$ and 5.65\% (13/230), respectively. There was no sex influence on prevalence of $\mathrm{C} 1$ anomalies $(P=0.33)$. Among isolated posterior arch anomalies, the type $\mathrm{A}$ and type $\mathrm{B}$ posterior arch defects were found in $3.77 \%$ and $0.3 \%$ of cases, respectively while type $\mathrm{C}, \mathrm{D}$ and $\mathrm{E}$ defects were not detected. The representative images of $\mathrm{Cl}$ arch anomalies were shown in the Fig. 1. The mean age of the patients was $37.2 \pm 15.9$ years. Age distribution for all subjects and those with $\mathrm{C} 1$ arch defects were noted in Table 1 . There was no statistically significant association between the age groups and prevalence of $\mathrm{C} 1$ arch anomalies $(P>0.05)$. Atlanto-occipital assimilation was noted in only one case of total study subjects (Fig. 1). However, this is not considered as the $\mathrm{Cl}$ anomaly.

\section{Discussion}

To the best of our knowledge, this is the first study to report the prevalence of congenital arch anomalies of $\mathrm{C} 1$ through the CT examinations of the cervical spine in Omani population. In the existing literature, the reported prevalence of $\mathrm{C} 1$ arch anomalies varied between $0.95 \%$ and $5.65 \%$ $[1,9-13]$. In a study by Geipel [9], congenital C1 defects were found in $4 \%$ of 1,613 adult specimens. Senoglu et al. [10] observed congenital anomalies of $2.95 \%$ in a cohort of 1354

Table 1. Age distribution of atlas arch anomalies

\begin{tabular}{cccc}
\hline Age group (yr) & $\begin{array}{c}\text { Absence of } \\
\text { anomalies }\end{array}$ & $\begin{array}{c}\text { Presence of } \\
\text { anomalies }\end{array}$ & Total \\
\hline $18-30$ & $273(94.8)$ & $15(5.2)$ & 288 \\
$31-40$ & $159(95.8)$ & $7(4.2)$ & 166 \\
$41-50$ & $69(93.2)$ & $5(6.8)$ & 74 \\
$51-60$ & $61(98.4)$ & $1(1.6)$ & 62 \\
$61-70$ & $38(97.4)$ & $1(2.6)$ & 39 \\
$71-80$ & $24(100)$ & $0(0)$ & 24 \\
$\geq 81$ & $10(100)$ & $0(0)$ & 10 \\
\hline
\end{tabular}

Values are presented as number (\%). cases from United States. In a cohort of 1153 mainly Asian patients from Korea, Kwon et al. [11]. have found $\mathrm{C} 1$ defects only in $0.95 \%$ of cases. Guenkel et al. [12]. reported defects in $3.8 \%$ of 1,069 cases from Switzerland. A recent study by Hyun et al. [13], have noted congenital $\mathrm{C} 1$ arch anomalies of 5.65\% among 3,273 subjects from United States. Evidence from these studies suggests that prevalence of $\mathrm{C} 1$ anomalies is more common in Caucasians when compared to Asians [10-13]. In the present study, the reported prevalence of $\mathrm{C} 1$ arch anomalies was $4.37 \%$. It is relatively high when compared to other reported studies [1,9-12]. However, it is low when compared to a recent study by Hyun et al. [13].

Posterior arch anomalies are more common than anterior arch anomalies. This can be explained based on the fact that the posterior arch develops from two ossification centers and the possibility of non-fusion of these centers is very high [1]. Type A posterior arch anomaly occurs when there is failure of fusion in the bilateral ossification centers, hence, it is the most common. Other types of posterior arch anomalies, and anterior arch anomalies are less common, because they occur when there is a defect in any one of the three ossification centers [1]. In the present study, type A posterior arch anomaly was found to be the most common, followed by type B posterior arch anomaly, other types of posterior arch anomalies were not detected. The reported prevalence of various types of posterior arch anomalies were described in Table 2 [1, 9-13]. In all these studies, type A was the most common. Next to type A, type B anomaly was frequently reported while type $\mathrm{C}$ and type $\mathrm{E}$ were rarely observed and type $\mathrm{D}$ was not detected. In recent study by Hyun et al. [13], females had a significantly higher prevalence than males. Contrary to this study, in the present study, the prevalence rate of $\mathrm{C} 1$ arch anomalies was similar in both sex. Occipitalisation is reported to occur in $0.08 \%$ to $3 \%$ of the general population without any sex difference in prevalence [14]. In the present study, it was observed in only one case of the total study sub-

Table 2. Prevalence of different types of posterior arch anomalies in different studies

\begin{tabular}{|c|c|c|c|c|c|c|c|}
\hline Authors & Country of study & Screening method & Type A & Type B & Type C & Type D & Type E \\
\hline Currarinoe et al. [1] & United States & CT scan & $3 \%-4 \%$ & $0.69 \%$ & - & - & - \\
\hline Geipel [9] & NA & Autopsy & $4 \%$ & - & - & - & - \\
\hline Senoglu et al. [10] & United States & CT scan, bone, autopsy & $2.60 \%$ & $0.54 \%$ & - & - & $0.18 \%$ \\
\hline Kwon et al. [11] & Korea & CT scan & $0.78 \%$ & $0.17 \%$ & - & - & - \\
\hline Guenkel et al. [12] & Switzerland & CT scan & $3.20 \%$ & $0.2 \%$ & & - & - \\
\hline Hyun et al. [13] & United States & CT scan & $4.60 \%$ & 0.45 & 0.06 & - & 0.03 \\
\hline Present study & Oman & CT scan & $3.77 \%$ & $0.3 \%$ & - & - & - \\
\hline
\end{tabular}

Type A: failure of fusion of two hemi arches; Type B: defect in one side of the arch; Type C: defects on both sides of arch; Type D: absence of arch except posterior tubercle; Type E: absence of whole arch including tubercle [1]. CT, computed tomography; NA, not available. 
jects.

Generally, the congenital anomalies of $\mathrm{C} 1$ are asymptomatic incidental findings [15]. Majority of the anomalies are detected during investigations of neck pain and stiffness or trauma of head and neck region. There are many clinical cases of symptomatic $\mathrm{Cl}$ arch anomalies particularly posterior arch anomalies. The reported symptoms of $\mathrm{C} 1$ arch defects include myelopathy, anterior rachischisis, cervical degenerative disc disease, occipital headache and weakness in upper and lower limbs $[7,8,16,17]$. Most of the neurological symptoms are due to atlantoaxial instability caused by the defects in anterior arch or posterior arch or combined defects. The baseline data of congenital anomalies of $\mathrm{C} 1$ reported in the present study may be clinically important in identifying the specific type of anomaly in order to distinguish it from fractures, in the setting of cervical trauma and proper management.

The present study has following limitations. Since, our study being a single-centered, it is relatively difficult to estimate the rare types of posterior arch anomalies. A future prospective study involving the subjects from more health centers and exploring the correlation of anomalies with associated clinical symptoms and cervical spine degenerative diseases would be ideal.

In conclusion, The prevalence rate of $\mathrm{C} 1$ arch anomalies is relatively high in Omani subjects. The baseline data $\mathrm{C} 1$ anomalies reported in the present study has a great impact on clinical practice, due to the fact that studying and evaluating the types of congenital anomalies helps in their accurate diagnosis and early intervention.

\section{ORCID}

Ghaliya Al Hinai: https://orcid.org/0000-0001-9173-2554

Mai Al Shandoodi: https://orcid.org/0000-0002-6510-1131

Srinivasa Rao Sirasanagandla:

https://orcid.org/0000-0002-7261-1666

Salwa Al Sarhani: https://orcid.org/0000-0002-5638-1215

Humoud Al Dhuhli:

https://orcid.org/0000-0003-2442-496X

Sanjay Jaju: https://orcid.org/0000-0002-9381-1528

Mohamed Al Mushaiqri:

https://orcid.org/0000-0002-2820-8968

\section{Author Contributions}

Conceptualization: GAH, SRS, HAD, MAM. Data acquisition: GAH, MAS, SRS, SAS. Data analysis or interpretation: SRS, HAD, SJ, MAM. Drafting of the manuscript: GAH, MAS, SRS, SAS. Critical revision of the manuscript: HAD, SJ, MAM. Approval of the final version of the manuscript: all authors.

\section{Conflicts of Interest}

No potential conflict of interest relevant to this article was reported.

\section{References}

1. Currarino G, Rollins N, Diehl JT. Congenital defects of the posterior arch of the atlas: a report of seven cases including an affected mother and son. AJNR Am J Neuroradiol 1994;15:24954.

2. Dorne HL, Lander PH. CT recognition of anomalies of the posterior arch of the atlas vertebra: differentiation from fracture. AJNR Am J Neuroradiol 1986;7:176-7.

3. Karavelioglu E, Kacar E, Karavelioglu A, Gonul Y, Guven M. Congenital defect of the anterior arch of the atlas: a case report and review of the literature. Neurol India 2014;62:303-4.

4. Kazanci B, Kahveci R, Ekici MA, Guclu B. Isolated fracture of anterior arch of atlas in a child: case report and review of the literature. Injury 2013;44:1956-8.

5. Petre BM, Karp JE, Riley LH 3rd. Athletic cervical spine injury in the setting of fusion failure of the anterior and posterior atlas. Orthopedics 2012;35:e1449-52.

6. Park Y, Kim SM, Lee YT, Yoo JH, Oh HC, Ha JW, Sung SY, Yoon HK, Chang JH, Jung JY. Congenital anomaly of the atlas misdiagnosed as posterior arch fracture of the atlas and atlantoaxial subluxation. Clin Orthop Surg 2014;6:96-100.

7. Klimo P Jr, Blumenthal DT, Couldwell WT. Congenital partial aplasia of the posterior arch of the atlas causing myelopathy: case report and review of the literature. Spine (Phila Pa 1976) 2003;28:E224-8.

8. Pasku D, Katonis P, Karantanas A, Hadjipavlou A. Congenital posterior atlas defect associated with anterior rachischisis and early cervical degenerative disc disease: a case study and review of the literature. Acta Orthop Belg 2007;73:282-5.

9. Geipel P. Zur Kenntnis der Spaltbildung des Atlas und Epistropheus. IV. Teil [Studies on the fissure formation of the atlas and epistropheus. IV]. Zentralbl Allg Pathol 1955;94:19-84. German.

10. Senoglu M, Safavi-Abbasi S, Theodore N, Bambakidis NC, Crawford NR, Sonntag VK. The frequency and clinical significance of congenital defects of the posterior and anterior arch of the atlas. J Neurosurg Spine 2007;7:399-402. 
11. Kwon JK, Kim MS, Lee GJ. The incidence and clinical implications of congenital defects of atlantal arch. J Korean Neurosurg Soc 2009;46:522-7.

12. Guenkel S, Schlaepfer S, Gordic S, Wanner GA, Simmen HP, Werner CM. Incidence and variants of posterior arch defects of the atlas vertebra. Radiol Res Pract 2013;2013:957280.

13. Hyun G, Allam E, Sander P, Hasiak C, Zhou Y. The prevalence of congenital C1 arch anomalies. Eur Spine J 2018;27:1266-71.

14. Martellacci S, Ben Salem D, Méjean N, Sautreaux JL, Krausé D. A case of foramen magnum syndrome caused by atlantooccipital assimilation with intracanal fibrosis. Surg Radiol
Anat 2008;30:149-52.

15. Junewick JJ, Chin MS, Meesa IR, Ghori S, Boynton SJ, Luttenton CR. Ossification patterns of the atlas vertebra. AJR Am J Roentgenol 2011;197:1229-34.

16. Sharma A, Gaikwad SB, Deol PS, Mishra NK, Kale SS. Partial aplasia of the posterior arch of the atlas with an isolated posterior arch remnant: findings in three cases. AJNR Am J Neuroradiol 2000;21:1167-71.

17. Wang K, Li X, Lou H, Luo B. Recurrent attacks of headache and neck pain caused by congenital aplasia of the posterior arch of atlas in an adult. BMJ Case Rep 2010;2010:bcr0520103053. 